\title{
The Face Shape and Golden Ratio Classification In Turkish Healthy Population
}

\author{
Sema Polat ${ }^{1}$, Ayse Gul Kabakcl², Yigit Cevik³ ${ }^{3}$ Ahmet Hilmi Yucel ${ }^{4}$ \\ ${ }^{1}$ Department of Anatomy, Cukurova University, Balcali/Adana, Turkey. ${ }^{2}$ Department of Anatomy, Cukurova \\ University, Balcali/Adana, Turkey. ${ }^{3}$ Department of Anatomy, Cukurova University, Balcali/Adana, Turkey. \\ ${ }^{4}$ Department of Anatomy, Cukurova University, Balcali/Adana, Turkey.
}

\section{ABSTRACT}

\section{BACKGROUND}

Beauty indicates a specific proportion system. It comprises facial height, width, and symmetry. A beautiful and an attractive face or facial morphology, which is affected by many factors such as social, cultural, ethnic, racial, climate, gender, age, socioeconomic, nutritional, and genetic is a subjective concept. We wanted to determine the facial morphology, golden ratio, and classify the face shape, in Turkish healthy adults.

\section{METHODS}

This is a descriptive study conducted among two hundred twenty-eight (139 females; 89 males) subjects aged between 18 and 25 years. Physiognomic facial height, the width of face, face golden ratio, morphological facial height, facial index were measured. Based on the face index, the face shape was classified as hypereuryprosopic, euryprosopic, mesoprosopic, leptoprosopic, and hyperleptoprosopic. Also, the face shape was determined according to the golden ratio. Statistical analysis was done by SPSS Ver. 22. Chi-Square Test was used to determine the differences between gender and face measurements. A p value of $<0.05$ value was considered as significant.

\section{RESULTS}

Out of 228 subjects, face shape according to golden ratio was normal in 11 female subjects, short in 128 female subjects. Also, in males, the same parameter was normal in 10 subjects, short in 72, and long in 7 subjects. On the other hand, significant differences were found between the genders. Hypereuroprosopic face type was the least observed in males but not in females.

\section{CONCLUSIONS}

The facial shape data may be valuable for evaluating various disorders and variations for plastic surgeons and orthodontists and other clinicians.

\section{KEY WORDS}

Face Shape, Gender Differences, Golden Ratio, Turkish Population
Corresponding Author: Dr. Sema Polat, Cukurova University, Faculty of Medicine, Department of Anatomy, Balcali/Adana, Turkey.

E-mail:sezaoz@hotmail.com

DOI: $10.14260 /$ jemds/2020/24

Financial or Other Competing Interests: None.

How to Cite This Article: Polat S, Kabakci AG, Cevik Y, et al. The face shape and golden ratio classification in Turkish healthy population. J. Evolution Med. Dent. Sci. 2020;9(02):111-115, DOI: 10.14260/jemds/2020/24

Submission 30-10-2019,

Peer Review 24-12-2019,

Acceptance 01-01-2020,

Published 13-01-2020.

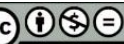




\section{BACKGROUND}

Beauty indicates a specific proportion system. It comprises facial height, width, and symmetry. A beautiful and an attractive face or facial morphology, which is affected by many factors such as social, cultural, ethnic, racial, climate, gender, age, socio-economic, nutritional, and genetic is a subjective concept.(1-5) The face is anterior part of the head lying transversely between the ears and longitudinally from the chin to the hairline. Also, it includes the forehead, eyes, nose, mouth and chin.(5) The face beauty is evaluated with harmony of proportions, facial symmetry, neonate features, averages, the geometrical attributes of facial features. Ideal proportion for beauty is accepted as 1.618.(4,6,7) This ratio is stated as golden ratio and considered as a universal facial aesthetical standard. The deviation of golden ratio can show the facial abnormalities development.(2) Analysis of facial parameters are necessary in many fields such as medicine, dentistry, plastic and reconstructive surgery, maxillofacial surgery, orthodontics, and prosthodontics for evaluation of facial trauma, congenital and traumatic deformities and identification of certain congenital malformations. Furthermore, the data is used in anthropology and forensic medicine for identification of racial and gender differences.(3,4) Face types are divided into five international anatomical categories: hypereuryprosopic, euryprosopic, mesoprosopic, leptoprosopic and hyperleptoprosopic.(3) On the other hand, the face shape based on the golden ratio was defined as normal, short and long face.(2) The facial dimensions are studied by direct methods such as caliper, and indirect anthropometric techniques such as camera and computer analysis. $(2,8-10)$

The objective of this study was to determine the facial morphologic parameters and classify face types and shapes based on both golden ratio and face index in Turkish healthy population.

\section{METHODS}

This descriptive study was carried out from the 228 healthy adult subjects ( 139 females; 89 males) aged $18-25$ years. The study was approved by Cukurova University Ethics Committee. Additionally, inclusion criteria for healthy adult subjects were no history of having facial surgical operation, or botulin toxin treatment or any neurologic disease such as neuromuscular diseases. The Frankfort horizontal plane was chosen to determine face classifications. This plane is described as reference plane. The lowest point of the orbita and the superior point of the external auditory meatus. Photographs were acquired using the photographic set up which comprised of a tripod supporting a Digital SLR Camera with fixed shooting values. (Canon EOS 80D; ISO 100 f/4.5). Tripod height was set up to subject's body height. In a standing position, each subject was asked to relax. The subject was positioned on a line marked on the floor. In all of the shoots a printed scale divided into milimetres with known dimensions were present. This printed scale gave us a life size opportunity. Acquired images were than transferred to a computer station. Measurements were made using Image $\mathrm{J} 1.52 \mathrm{a}$ with $1 / 100 \mathrm{~mm}$ sensitivity. The measurement process was explained to each subject and written permission was obtained from each tested subject before the measurements. All measurements were performed in the same way and the same condition. The measurements were taken from each subject by three different researchers (S.P., A.G.U., Y.C..). A form was used for quick recording. Two vertical and one horizontal measurement were taken. Every measurement was repeated three times by the same investigators and, the mean value of the measurements was taken. The anthropometric measurements were studied as follows and landmark points used in measuring of the parameters were: $n$ - nasion: the midpoint of the nasofrontal suture; gn - gnation: in the midline, the lowest point on the lower border of the chin; zy - zygomatic prominences, zygion: the most lateral point on the zygomatic arch.

\section{Vertical Measurements}

- $(\mathrm{PFH})$ Physiognomical Facial Height: The distance between the trichion and gnathion points.

- MHF) Morphological facial height: The distance between nasion and gnation.

\section{Horizontal Measurement}

- (FW) The Width of Face: The distance from the zygion on right side to zygion on left side.

\section{The Ratio of Facial Landmarks}

- (GR) Face Golden Ratio: The ratio of physiognomical facial height to the width of the face.

- (FI) Facial index: The ratio of morphological facial height and maximum face width.

\section{Formula Used}

$\mathrm{TFI}=(\mathrm{PFH} / \mathrm{FW}) \times 100$

Based on the face index (FI), the face shape was classified as: hypereuryprosopic (FI $\leq 78.9)$, euryprosopic $(79.0<\mathrm{FI} \leq$ 83.9), mesoprosopic ( $84.0 \leq \mathrm{FI} \leq 87.9$ ), leptoprosopic ( $88 \leq \mathrm{FI}$ $\leq 92.9$ ) and hyperleptoprosopic (FI $\geq 93.0$ ). Also, the golden ratio was 1.6. When the ratio was between 1.6 and 1.699, the shape was normal; the shape was long when its ratio was larger than 1.7; and when the ratio was smaller than 1.6; the shape was short. $(2,5,11,12)$ Measurements were made on the computer screen with an electronic caliper and estimations were expressed as millimeters. The SPSS 22.0 program was used for statistical analysis of the measurement results. From these measurements, face phenotype and, face golden ratio were calculated; In all statistical analyses; $p$ value under 0.05 was considered as statistically significant. The KolmogorovSmirnov test showed normality of distribution of the obtained data in both groups. Chi Square Test were applied to test the differences between genders and the categorical variables.

\section{RESULTS}

The value of face golden ratio classification between genders were measured in 228 healthy subjects (139 females and 89 males) were shown in Table 1 . In females, one hundred twenty-eight short face and eleven normal face were found. 
Also, in males, seventy-two short face, ten subjects normal face, and seven long face were calculated. The significant differences were found between females and males (Table 1). The classification of face golden proportion was shown in Figure 1. Additionally, the 1.618 ratio known as golden ratio was found only three females. However, no significant differences were found in face shape classification (Table 2), but important differences were noted in face shape classifications according to face golden ratio $(\mathrm{p}<0.001)$ (Table 3). The data was shown in Figure 2. In two hundred short face, one euryprosopic type, nineteen mesoprosopic type, forty-one leptoprosopic type, one hundred thirty-nine hyperleptoprosopic type were observed. In normal face, one euryprosopic type, ten mesoprosopic type, seven leptoprosopic type, three hyperleptoprosopic type were determined according to measurements. In long face shape, one hypereuroprosopic, one euryprosopic type, two mesoprosopic type, two leptoprosopic type, one hyperleptoprosopic type were measured.

\begin{tabular}{|c|c|c|c|}
\hline Gender & Short Face & Normal Face & Long Face \\
\hline Female(139) & $128(92.09 \%)$ & $11(7.91 \%)$ & $0(0.0 \%)$ \\
\hline Male(89) & $72(80.90 \%)$ & $10(11.23 \%)$ & $7(7.87 \%)$ \\
\hline $\mathrm{p}$ & \multicolumn{3}{|c|}{0.020} \\
\hline \multicolumn{2}{|c|}{ Table 1. Face Golden Ratio Classification between Genders } \\
\hline
\end{tabular}

\begin{tabular}{|c|c|c|c|}
\hline Gender & Face Shapes & $\mathbf{n}$ & $\mathbf{\%}$ \\
\hline & Hypereuroprosopic & 0 & $0 \%$ \\
Female (139) & Euryprosopic & 1 & $0.72 \%$ \\
& Mesoprosopic & 17 & $12.23 \%$ \\
& Leptoprosopic & 28 & $20.14 \%$ \\
& Hyperleptoprosopic & 93 & $66.91 \%$ \\
\hline \multirow{4}{*}{ Male (89) } & Hypereuroprosopic & 1 & $1.12 \%$ \\
& Euryprosopic & 2 & $2.25 \%$ \\
& Mesoprosopic & 14 & $15.73 \%$ \\
& Leptoprosopic & 22 & $24.72 \%$ \\
& Hyperleptoprosopic & 50 & $56.18 \%$ \\
\hline p & \multicolumn{3}{|c}{0.339} \\
\hline
\end{tabular}

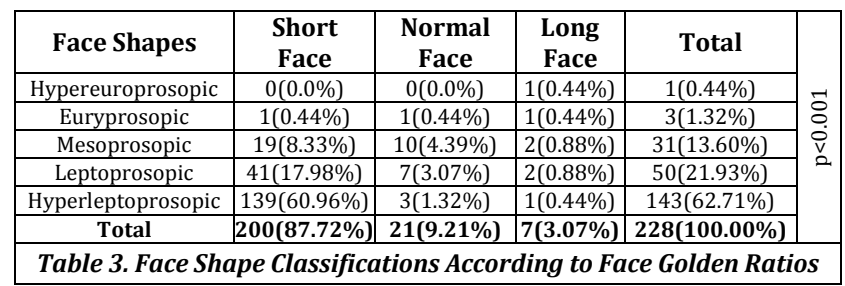

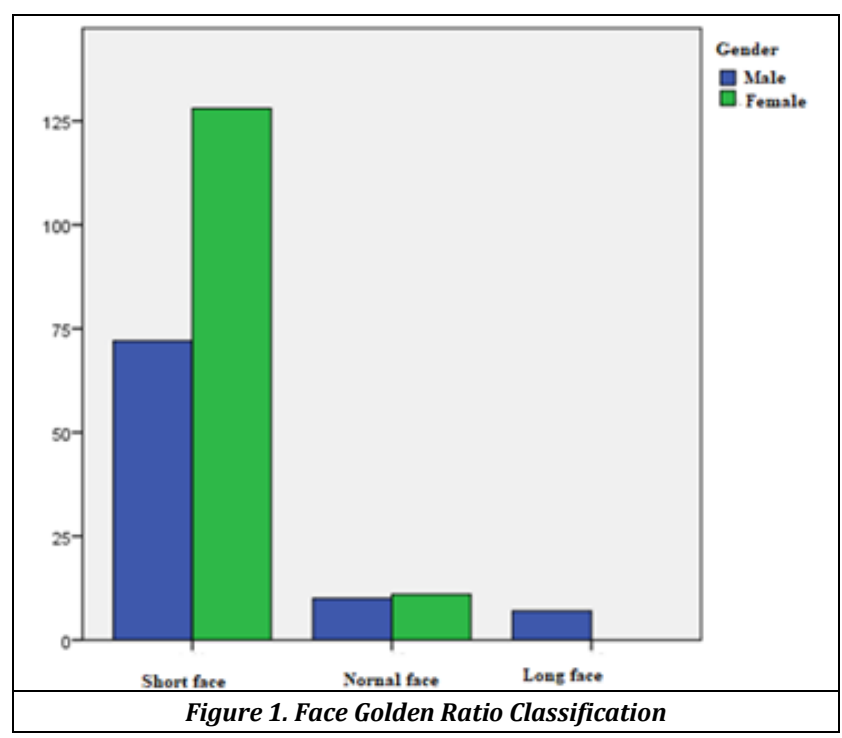

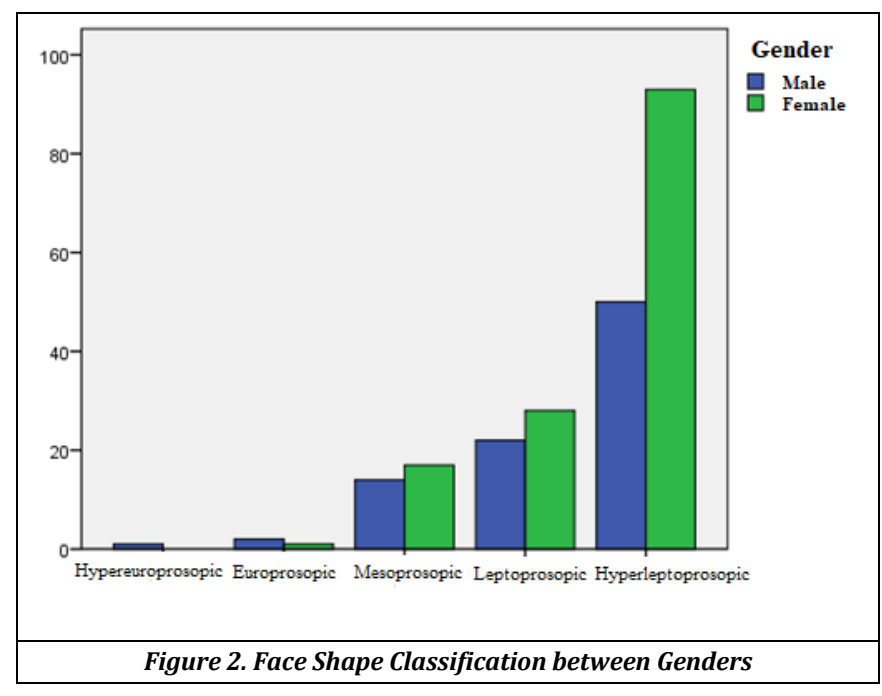

\section{DISCUSSION}

The facial shape evaluation can be important for earlier identification of progressive developmental abnormalities. These abnormalities can affect the morphology and functional values of soft tissues in the following stages. The golden ratio was used to define subjects with short and long face in population at risk of developing maxillofacial, respiratory, and sleep disorders. Also, the golden proportion is considered as a universal standard for aesthetical predictions, biological efficiency, and wellbeing, regardless of sex, age, and ethnicity.(2) On the other hand, the face features differ from races and ethnic groups (facial features may vary between race and ethnic groups). Face shapes are classified according to facial index.(5) The face shape was ratio between the physiognomic facial height and bizygomatic width measurement. When the ratio approximated to 1.6 , the shape was normal; the shape was long when its ratio was larger than 1.6; and when the ratio was smaller than 1.6, the shape was short.(2) Additionally, the golden ratio certain value is the phi number $(\Phi=\mathrm{a} / \mathrm{b}=(\mathrm{a}+\mathrm{b}) / \mathrm{a}=1.61803399 \ldots)$ named by Parthenon Phidias. This ratio is referred to as the Fibonacci ratio or the divine proportion. The ratio has been used in art, architecture, and in the beauty industry. $(1,6,13,14)$ The perception of the beauty or attractiveness has been determined with some facial points such as trichion, menton or nasion. The proportions matches with the golden ratio in more attractive faces.(14-16) In a classification of facial shapes based on golden ratio, In Malaysian Chinese population, face shape was normal in 16 subjects $(5$ males, 11 females $=1.6$ 1.699), short in 77 subjects (41 male, 36 female), and long in 7 subjects ( 4 male, 3 female). In Malaysian Indian population, face shape was normal in 20 subjects (10 male, 10 female), short in 75 (36 male, 39 female), and long in 5 (4 male, 1 female). In Malay population, the face shape was normal in 24 subjects ( 15 male, 9 female), short in 72 subjects ( 31 male, 41 female), and long in 4 subjects ( 4 male, 0 female). (2). In Indian females aged between $17-19$ years, 9 subjects $(24 \%)$ had a normal size, 5 subjects (13\%) had a long face. 24 subjects $(63 \%)$ had a short face, whereas in Indian males, face shape normal in 5 subjects (14\%), long in 6 subjects $(16 \%)$ and short in 26 subjects (70\%).(13) In present study, In females, one hundred twenty eight (128) short face and 
eleven (11) normal face were found. Also, in males, seventytwo (72) short face, ten subjects (10) normal face, and seven (7) long face were calculated. There are found significant difference in females and males. Due to these data, our result is similar to Malaysian Chinese, Malaysian Indians, Malay population, and Indians. The face shape seen the most common was short, whereas the least seen face shape was long face.

The face shape is classified into different types based on the facial index and these are the hypereuryprosopic, euryprosopic, mesoprosopic; leptoprosopic and hyperleptoprosopic faces.(17-20) Bedita Devi et al reported morphological facial index calculated according to Martin and Saller formula. The dominant phenotype face was mesoprosopic and leptoprosopic face, followed by euryprosopic type and followed by hyperleptoprosopic type, whereas the least seen type was hypereuroprosopic type.(5) In Indians, the frequency of the most common facial types was hypereuryprosopic type, followed by euryprosopic, whereas the hyperleptoprosopic type was no found.(21) In Kosovan males aged between 18-35 years, hypereuryprosopic type was in 8 subjects (1.4\%), euryprosopic type in 77 subjects (13.7\%), mesoprosopic type in $124(22.1 \%)$ leptoprosopic type in 175 subjects (31.2\%), and hyperleptoprosopic type in 177 subjects (31.6\%), whereas in Kosovan females aged between 18-35 years, hypereuryprosopic type was in 0 subjects $(0.0 \%)$, euryprosopic type in 9 subjects (4.7\%), mesoprosopic type in $32(16.6 \%)$ leptoprosopic type in 58 subjects (30.0\%), and hyperleptoprosopic type in 94 subjects (48.7\%) (8). In Haryanvi males and females population, hypereuryprosopic type was in 33 - 75 subjects, euryprosopic type in 72-58 subjects, mesoprosopic type in 149-105, leptoprosopic type in 37-57 subjects, and hyperleptoprosopic type in 9-5 subjects, respectively.(22) The most common type of facial shape of Japanese males was leptoprosopic (26.1\%) followed by mesoprosopic (24.3\%), hypereuryprosopic (23.6\%), euryprosopic (17.4\%), and hyperleptoprosopic (8.3\%). On the other hand, the most common type of facial shape of Japanese females was leptoprosopic (30.7\%) followed by hypereuryprosopic (23.2\%), mesoprosopic (21.5\%), hyperleptoprosopic (15.0\%), and euryprosopic (9.5\%) (10). In studies performed with different population, it was found significant difference in facial anthropometric differences between genders. ${ }^{(8,21,23,24)}$ Hyperleptoprosopic face $(38.5 \%)$ was the commonest type of face and was followed by leptoprosopic face $(30.1 \%)$, mesoprosopic face $(26.3 \%)$, europrosopic face (4.2\%), and hypereuryprosopic face $(1.0 \%)$ in Nigerian adults.(20) In Africans, leptoprosopic face was considered to be the commonest type of face.(25) In both Serbian adult male and female population, leptoprosopic face was the commonest type of face $(81.7 \%)$, and was followed by mesoprosopic face type, hyperleptoprosopic face type.(3) In Iranian males, mesoprosopic phenotype face was in $38.4 \%$ of subjects, whereas in females, euryprosopic face was in $51.7 \%$ of subjects. $(3,11)$ The most prevalent type of facial shape of Turkish male was hyperleptoprosopic (66.91\%) followed by leptoprosopic (20.14\%) mesoprosopic (12.23\%), euryprosopic $(0.72 \%)$ hypereuryprosopic $(0.0 \%)$. Moreover, the most common facial shape type of Turkish female was hyperleptoprosopic (56.18\%) followed by leptoprosopic
(24.72\%) mesoprosopic (15.73\%), euryprosopic (2.25\%) hypereuryprosopic (1.12\%).

In Arslan et al's study performed with 173 Turkish healthy young subjects aged between 17 and 25, the most common type of facial shape was leptoprosopic (36) followed by mesoprosopic, and euryprosopic in males, whereas euryprosopic type was in 34 subjects, leptoprosopic type in 29 subjects, and mesoprosopic type in 20 subjects in females. Also, there was low differences between face and gender.(26) In the other study done in Turkish population aged between 18 and 68, in females the most prevalent face types were euryprosopic (34.33\%) and mesoprosopic types (34.33\%), whereas the least seen type was hyperleptoprosopic type (3.94\%). Euryprosopic type (35.3\%), mesoprosopic (33.2\%), hypereuryprosopic (18.1\%), leptoprosopic (8.7\%), and hyperleptoprosopic (4.7\%) were seen in males.(9) In a study of Çiner's, the least seen face type was hypereuryprosopic type $(0.15 \%)$, whereas the most prevalent type was hyperleptoprosopic type (66.86\%), followed by leptoprosopic type (23.60\%), mesoprosopic type (8.77\%) and euryprosopic type $(0.60 \%)$ in subjects aged between 18 and 20. In subjects with 20 years and later, the most common type was hyperleptoprosopic type (59.41\%), followed by leptoprosopic type (26.76\%), mesoprosopic type (11.86\%) and euryprosopic type $(1.90 \%)$, and hypereuryprosopic (0.05\%).(27) When comparing the Turkish findings with this study, we observe that there are differences between studies of Arslan et al's and Özşahin et al's and our population data. However, there were similarities between Çiner's findings. We consider that these discrepancies could be a result of such factors like the measurement methods, genetic variables, nutritional status, socioeconomic status and demographic variables including age, weight and height. Additionally, this show that there can be differences in same races.

\section{CONCLUSIONS}

In the present study, we evaluated the mean values of physiognomic facial height, width of the face, and physiognomic facial index according to genders on Frankfort plane (this plane is described as the reference plane. The lowest point of the orbita and the superior point of the external auditory meatus). ${ }^{28}$ Also, we compared our data with other racial and ethnic groups. These data obtained from the Turkish population will provide important information to plastic surgeons, orthodontists and other clinicians in future for analysing developmental anomalies and/or structural disorders.

\section{REFERENCES}

[1] Pallett PM, Link S, Lee K. New golden ratios for facial beauty. Vision Research 2010;50(2):149-54.

[2] Packiriswamy V, Kumar P, Rao M. Identification of facial shape by applying golden ratio to the facial measurements: an interracial study in Malaysian population. North American Journal of Medical Sciences 2012;4(12):624-9. 
[3] Jeremić D, Kocić S, Vulović M, et al. Anthropometric study of the facial index in the population of Central Serbia. Archives of Biological Science Belgrade 2013;65(3):1163-8.

[4] Milutinovic J, Zelic K, Nedeljkovic N. Evaluation of facial beauty using anthropometric proportions. Hindawi Publishing Corporation: The Scientific World Journal 2014;2014:428250.

[5] Devi BT, Singh TN, Singh SJ, et al. Facial morphology and facial index: a study on secular trend of Meitei male population of Bishnupur district Manipur India. International Journal of Anatomy Research 2016;4(4):3279-83.

[6] Akdeniz F. Altın Oran: Doğada, Sanatta, Mimaride ve Fibonacci Sayıları. 1st edn. Adana: Nobel Kitabevi 2007.

[7] Dantcheva A, Dugelay JL. Assessment of female facial beauty based on anthropometric, non-permanent and acquisition characteristics. Multimed Tools Applications 2015;74(24):11331-5.

[8] Rexhepi A, Meka V. Cephalofacial morphological characteristics of Albanian Kosova population. International Journal of Morphology 2008;26(4):935-40.

[9] Özşahin E, Kızılkanat E, Boyan N, et al. Evaluation of face shape in Turkish individuals. International Journal of Morphology 2016;34(3):904-8.

[10] Mamun A, Hossain G, Lestrel PE, et al. Gender differential of craniofacial measurements among university students in Japan. Anthropologist 2018;31(1-3):80-5.

[11] Jahanshahi M, Golalipour MJ, Heidari K. The effect of ethnicity on facial anthropometry in Northern Iran. Singapore Medical Journal 2008;49(11):940-3.

[12] Azizi M, Hassanzadeh G, Barbarestani M, et al. Comparative anthropometric analysis of facial dimensions and types in Qazvin, Iran and DeraGhazi Khan Pakistan. Anatomical Sciences 2014;11(3):119-26.

[13] Saraswathi P. The golden proportion and its application to the human face. European Journal of Anatomy 2007;11(3):177-80.

[14] Prokopakis EM, Vlastos IM, Picavet V, et al. The golden ratio in facial asymetry. Rhinology 2013;51(1):18-21.

[15] Jefferson Y. Facial beauty establishing a universal standard. International Journal of Orthodontics 2004;15(1):9-22.

[16] Jahanbin A, Basafa M, Alizadeh Y. Evaluation of the divine proportion in the facial profile of young females. Indian Journal of Dental Research 2008;19(4):292-6.
[17] Maina MB, Mahdi O, Kalayi GG. Craniofacial forms among three dominant ethnic groups of Gombe State, Nigeria. International Journal of Morphology 2012;30(1):211-6.

[18] Yesmin T, Thwin SS, Urmi SA, et al. A study of facial index among Malay population. Hindawi Publishing Corporation, Journal of Anthropology 2014;2014:726974.

[19] Kumari KL, Babu PVSSV, Kumari PK, et al. A study of cephalic index and facial index in Visakhapatnam, Andhra Pradesh, India. International Journal of Research in Medical Sciences 2015;3(3):656-8.

[20] Okwesili OR. Craniofacial dimensions in the Igbos of Enugu. Thesis of Doctor of Philosophy, Nigeria: Nigeria University College of Medicine, 2016;1-160.

[21] Shah T, Thaker MB, Menon SK. Assessment of cephalic and facial indices: a proof for ethnic and sexual dimorphism. Journal of Forensic Science and Criminology 2015;3(1):1-15.

[22] Kumar M, Lone MM. The study of facial index among Haryanvi adults. International Journal of Science and Research 2013;2(9):51-3.

[23] Zhuang Z, Landsittel D, Benson S, et al. Facial anthropometric differences among gender ethnicity and age groups. The Annals of Occupational Hygiene 2010;54(4):391-402.

[24] Balaei TA, Sutherland K, De Cistulli P, et al. Prediction of obstructive sleep apnea using facial landmarks. Physiological Measurement 2018;39(9):094004.

[25] Torres-Restrepo AM, Quintero-Monsalve AM, GiraldoMira JF, et al. Agreement between cranial and facial classification through clinical observation and anthropometric measurement among Envigado school children. BMC Oral Health 2014;14:50.

[26] Arslan SG, Genç C, Odabaş B, et al. Comparison of facial proportions and anthropometric norms among Turkish young adults with different face types. Aesthetic Plastic Surgery 2008;32(2):234-42.

[27] Çiner R. Türkiye kadınlarının antropolojisi. Ankara Üniversitesi Dil Tarih Cografya Fakültesi Dergisi 1960;18(3-4):161-206.

[28] Hegde V. Significance of the Frankfort mandibular plane angle in prosthetic management of partially or completely edentulous patients with Class II malocclusions. The Journal of Indian Prosthodontic Society 2005;5(4):175-9. 